\title{
"INVESTIGAÇÃO DA TOXICIDADE DO EXTRATO DE SEMENTES DE Stryphnodendron fissuratum (MIMOSOIDEAE) COM PROPRIEDADES NEUTRALIZANTES SOBRE A PEÇONHA DE Bothrops leucurus"
}

\author{
R. P. F. SILVA, E. V. PONTUAL, J. E. S SILVA, M. M. S. SILVA
}

Universidade Federal Rural de Pernambuco, Departamento de Ciências Biológicas, Departamento de Morfologia e Fisiologia Animal.

\section{E-mail: Renattapriscilla2905@outlook.com}

RESUMO - Este trabalho descreve a investigação: 1. da eficiência de modelo de fitotoxicidade no monitoramento da virulência da peçonha de B. leucurus; e 2. do efeito do extrato de sementes de S. fissuratum sobre a ação fitotóxica da peçonha. Sementes de $S$. fissuratum, foram secas e um extrato foi obtido em solução de etanol/água $70 \%(\mathrm{v} / \mathrm{v})$. Sementes de Lactuca sativa (alface) foram colocadas para germinar em placas de Petri forradas com papel filtro embebido com solução de peçonha de B. leucurus (2 $\mathrm{mg} / \mathrm{mL})$. Após incubação $\left(72 \mathrm{~h}, 28 \pm 5^{\circ} \mathrm{C}\right)$, foram determinados indices de germinação das sementes (IG) e de crescimento relativo (ICR) das radiculas. Estes ensaios foram repetidos em presença do extrato de sementes. $O$ tratamento com a peçonha não alterou os valores de $I G$, mas resultou em forte redução no crescimento das radículas (ICR = $25,87 \pm 1,2 \%)$ quando comparado ao grupo controle $(I C R=100 \pm 5,92 \%)$, indicando que o modelo de fitotoxicidade foi eficiente em monitorar a virulência da peçonha. $O$ extrato de sementes de $S$. fissuratum reduziu significativamente a fitotoxicidade da peçonha, resultando em valores de ICR iguais a 32,84 $\pm 1,0 \%$ e 45,27 $\pm 3,08 \%$ nas concentrações de 2,5 e $5 \mu \mathrm{L} / \mathrm{mL}$, respectivamente. Em conclusão, o modelo de fitotoxicidade para plântulas foi eficiente para monitorar virulência da peçonha de $B$. leucurus, a qual foi reduzida em presença do extrato de sementes de S. fissuratum.

Palavras-chave: Antipeçonha, Alface, Fitotoxicidade, Jararaca

ABSTRACT - This work describes the investigation of: 1. the efficiency of a phytotoxicity model in monitoring the virulence of B. leucurus venom; and 2. the effect of the $S$. fissuratum seed extract on the phytotoxic action of the venom. Seeds of S. fissuratum were dried and an extract was obtained in $70 \%(v / v)$ ethanol / water solution. Seeds of Lactuca sativa (lettuce) were placed to germinate in Petri dishes lined with filter paper soaked with a B. leucurus venom solution $(2 \mathrm{mg} / \mathrm{mL})$. After incubation $\left(72 \mathrm{~h}, 28 \pm 5^{\circ} \mathrm{C}\right)$, seed germination (GI) and relative growth index (ICR) indexes were determined. These tests were repeated in the presence of the seed extract. The treatment with the venom did not alter the GI values, but resulted in a strong reduction in the radicle growth (ICR $=25.87$ $\pm 1.2 \%)$ when compared to the control group (ICR $=100 \pm 5.92 \%)$, indicating that the phytotoxicity model was efficient in monitoring venom virulence. Seed extract from $S$. fissuratum significantly reduced the venom phytotoxicity, resulting in ICR values of 32.84 $\pm 1.0 \%$ and $45.27 \pm 3.08 \%$ at concentrations of 2.5 and $5 \mu L / m L$, respectively. In 
conclusion, the seedling phytotoxicity model was efficient to monitor virulence of the $B$. leucurus venom, which was reduced in the presence of the $S$. fissuratum seed extract.

Key words: Anti-venom, Lettuce, Phytotoxicity, Jararaca

\section{INTRODUÇÃO}

O gênero Bothrops no Brasil é considerado o principal causador de acidentes ofídicos, contribuindo com 90,3\% do total de acidentes com serpentes peçonhentas (FUNASA, 2001). O gênero Stryphnodendron está presente na região sulamericana, e é considerado tipicamente brasileiro. Leguminosas pertencentes à Família Fabaceae, subfamília Mimosoidea, as espécies desse gênero têm-se destacado pela intoxicação causada em ruminantes de pequeno e grande porte e também pela presença de moléculas bioativas com ação medicinal (ALBUQUERQUE et al., 2011).

Os testes de toxicidades têm sido comumente realizados em animais experimentais, todavia cada vez mais a utilização de espécies vegetais especificas pode ser uma alternativa confiável para avaliar o potencial tóxico de muitos compostos e contribuir como uma espécie de triagem ou até mesmo observação inicial da ação das toxinas presentes em peçonhas. Os testes de toxicidade utilizando organismos vegetais foram constatados por vários pesquisadores que realizaram de forma concomitante modelos testes animais e vegetais (PALMIERI et al., 2016).

Sendo assim, este trabalho descreve: I. A avaliação da eficiência do modelo de fitotoxicidade para plântulas no monitoramento da virulência da peçonha de Bothrops leucurus e II. A investigação do efeito do extrato de sementes de S. fissuratum sobre a ação fitotóxica da peçonha.

\section{MATERIAIS E MÉTODOS}

A toxicidade da peçonha de Bothrops leucurus foi avaliada utilizando sementes de Lactuta sativa (alface), seguindo a metodologia descrita por Tiquia et al. (1996). Água mineral foi usada como controle negativo e uma solução de dicromato de potássio $(1 \%, \mathrm{~m} / \mathrm{v})$ foi utilizada como controle positivo. Cada ensaio, realizado em duplicata, correspondeu a uma placa de Petri $(90 \times 15 \mathrm{~mm})$ onde 15 sementes foram colocadas sobre papel filtro embebido com 2,0 $\mathrm{ml}$ de peçonha $(0,2 \mathrm{mg} / \mathrm{mL})$ ou das soluções controle. Em seguida, as placas foram vedadas com Parafilm ${ }^{\circledR}$ para evitar a evaporação e incubadas por 72 horas a $20 \pm 2{ }^{\circ} \mathrm{C}$. Após esse período, o número de sementes germinadas em cada placa, bem como o comprimento das radículas foram registrados. Os ensaios foram considerados válidos quando a germinação foi igual ou maior que $90 \%$ no controle negativo. O índice de crescimento relativo (ICR) e o índice de germinação (IG) foram calculados de acordo com as equações: $\mathrm{IG}=(\mathrm{SGT} / \mathrm{SGC}) \mathrm{x}$ 100 e ICR $=(\mathrm{CRT} / \mathrm{CRC}) \times 100$; onde: SGT é o número de sementes germinadas nas amostras teste e SGC o número de sementes germinadas no controle; CRT é o comprimento da radícula no tratamento teste; CRC é o comprimento da radícula no controle negativo.

\section{RESULTADOS E DISCUSSÃO}

A toxicidade de $S$. fissuratum para bovinos tem sido reportada, o que pode acarretar em apresentar complicações decorrentes de úlceras multifocais no abomaso, hemorragias gastrintestinais e necrose hepática (Rodrigues et al. 2005). Contudo, nosso Grupo de Pesquisa tem trabalhado na prospecção de componentes vegetais com potencial antiofídico e, 
interessantemente, apesar da reconhecida toxicidade para bovinos, nossos resultados prévios revelaram que o extrato de $S$. fissuratum não interferiu na sobrevivência de fêmeas de camundongos swiss (Mus musculus). Ainda, demonstramos que este extrato reduziu a letalidade da peçonha sobre esses animais. Em adição, nossos trabalhos anteriores demonstraram que o extrato hidroalcoólico de S. fissuratum, contendo taninos hidrolisáveis, flavonoides, derivados cinâmicos, fenilpropanoides, triterpenos, esteroides e saponinas, foi eficiente na neutralização das propriedades enzimáticas (fosfolipásica, coagulante e proteolítica) da peçonha de Bothrops leucurus (Silva, 2010). Neste trabalho, nós avaliamos a eficiência do modelo de fitotoxicidade para plântulas no monitoramento da virulência da peçonha de Bothrops leucurus e o efeito do extrato de sementes de $S$. fissuratum sobre a ação fitotóxica dessa peçonha. $\mathrm{O}$ ensaio de fitotoxicidade utilizando sementes de $L$. sativa revelou que a peçonha não interferiu significativamente $(\mathrm{p}=0,35)$ na quantidade de sementes germinadas em relação ao controle negativo (Figuras 1A e 1C), contudo, forte ação tóxica da peçonha foi refletida pelo crescimento das plântulas significativamente $(p=0,003)$ reduzido quando comparado ao controle negativo (Figuras 1B e 1C). Quando a peçonha foi previamente incubada com o extrato de sementes de $S$. fissuratum, foi possível detectar a redução do seu potencial fitotóxico, refletido pelo maior crescimento das plântulas (Figuras 1B e 1C).

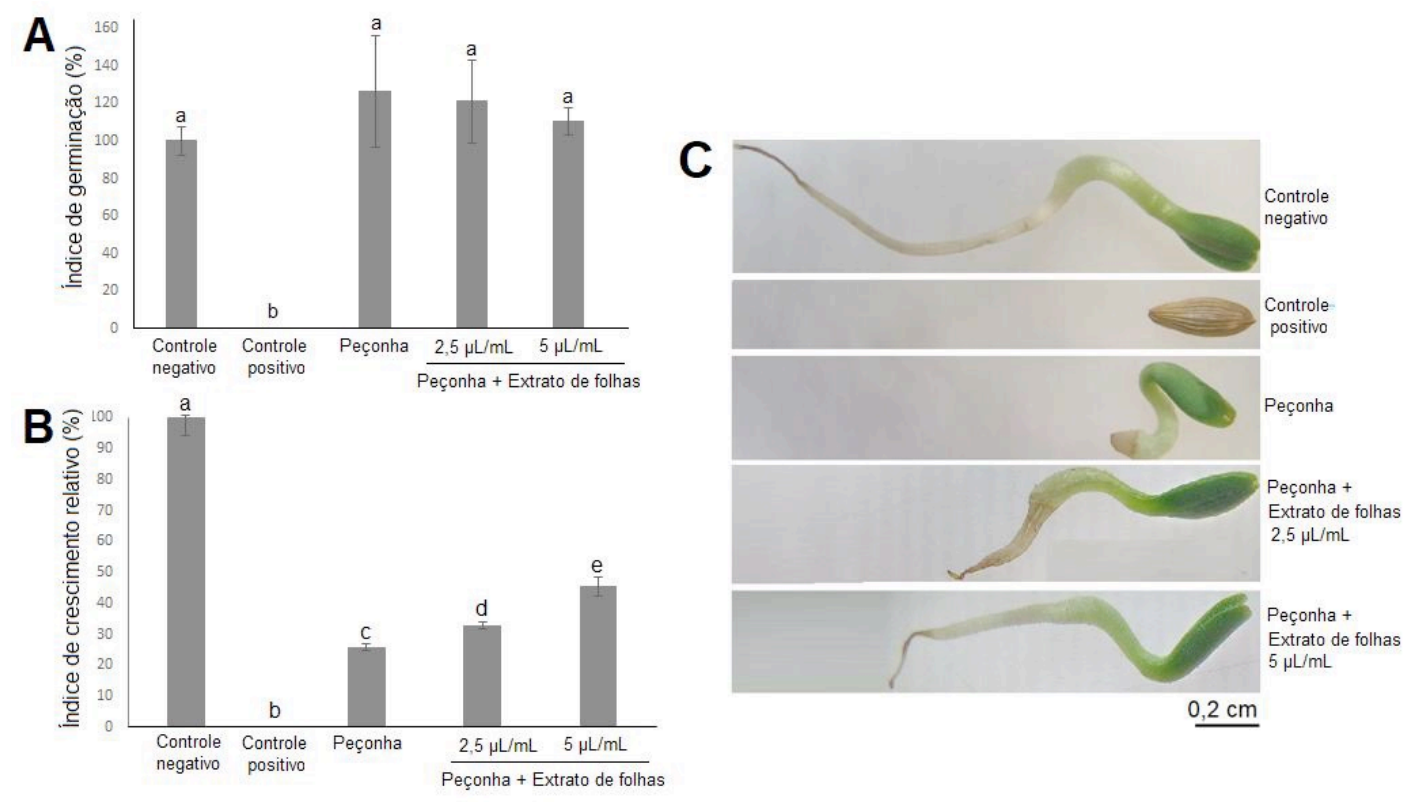

Figura 1. Efeito do extrato de sementes de $S$. fissuratum na fitotoxicidade da peçonha de $B$. leucurus. (A) índices de germinação (\%) de sementes de L. sativa. (B) Índices de crescimento relativo das plântulas de L. sativa. (C) Aspecto das plântulas se L. sativa germinadas a partir de sementes tratadas com o controle negativo (água mineral), controle positivo (dicromato de potássio $1 \% \mathrm{~m} / \mathrm{v})$, peçonha de B. leucurus $(0,2 \mathrm{mg} / \mathrm{mL})$ e peçonha previamente incubada com o extrato de sementes de $S$. fissuratum a 2,5 e $5 \mu \mathrm{L} / \mathrm{mL}$.

A ausência de germinação no controle positivo assegura que os testes foram realizados em condições adequadas para esta investigação e juntos os resultados relatados aqui indicam que ensaio utilizando sementes de $L$. sativa foi eficiente para monitorar a virulência da peçonha de B. leucurus. Adicionalmente, esses dados, juntamente com nossos relatos prévios, corroboram com a hipótese de que o extrato de sementes de S. fissuratum apresenta um interessante potencial antiofídico. 


\section{CONCLUSÃO}

O extrato de sementes de $S$. fissuratum incubado com a peçonha de B. leucurus reduziu o potencial virulento da mesma contribuindo para a hipótese de esse que extrato vegetal pode ser considerado um potente agente antiofídico. Todavia testes adicionais de toxicidade deverão ser realizados.

\section{REFERÊNCIAS}

ALBUQUERQUE, R.F.; NETO-E. J.; FREITAS S.H.; DÓRIA R.G.S.; SAURINI N.O.; COLODEL E.M.; CORREA-R. F.; MENDONÇA F.S. Abortion in goats after experimental administration of Stryphnodendron fissuratum (Mimosoideae). Toxicon 58 (2011) 602-605. 2011

FUNASA. Manual de Diagnóstico e Tratamento de Acidentes por Animais Peçonhentos. Ministério da Saúde. 2 ed. Brasília. p.14, 2001.

OCCHIONI, E. M. L. Considerações taxonômicas no gênero Stryphnodendron Mart. (Leguminosae-Mimosoideae) e distribuição geográfica das espécies. Acta Botânica Brasileira, v.4, n.2, p.153-158, 1990.

PALMIERI, M. J. et al. Cytogenotoxic Effects of Spent Pot Liner (SPL) and Its Main Components on Human Leukocytes and Meristematic Cells of Allium cepa. Water, Air, \& Soil Pollution, v. 227, n. 5, p. 156, 23 maio 2016.

Rodrigues A.S., Chaves N.S.T., Damasceno A.D., Trindade B.R., Martins G.H.L. \& Arantes A.F. 2005. Aspectos clínicos da intoxicação experimental de bovinos pelos frutos de Stryphnodendron fissuratum Mart. ("rosquinha"). Ciênc. Anim. Bras. 6:119-126.

Silva, N.L.A., Miranda, F.A.A., Conceição, G.M., 2010. Triagem fitoquímica de plantas do cerrado, da área de proteção ambiental do Inhamun, Caxias, Maranhão. Scientia Plena 6.

TIQUIA, S.M., Tam, N.F.Y., Hodgkiss. I.J., 1996. Effects of composting on phytotoxicity of spentpig-manure sawdust litter. Environ. Pollut. 93, 249-256.

\section{AGRADECIMENTOS}

CNPQ, UFRPE, UFPE, CAPES. 